\title{
An Assessment of the Uber App's Normative Practice
}

\author{
Christine Boshuijzen-van Burken \\ Linnaeus University, Växjö, Sweden \\ Eindhoven University of Technology, Eindhoven, The Netherlands \\ christinevanburken@gmail.com \\ Darek M. Haftor \\ Uppsala University, Uppsala, and Linnaeus University, Växjö, Sweden \\ darek.haftor@im.uu.se
}

\begin{abstract}
This study analyzes a complex case in society, namely, how to distinguish ride-sharing applications, such as Uber, from ordinary taxi enterprises. We conduct a structural analysis of normative practices with distinctions at the following levels: (1) aspects; (2) radical types, genotypes, and phenotypes; (3) part-whole, enkaptic relationships, and interlinkages; and (4) the distinction between qualifying and foundational functions as it is captured in the theory of normative practices. We conclude that the genotype of taxi matchmaking enterprises, of which Uber is an example, represents a novel normativity that could positively serve society and also produce normative challenges, depending on its governance. Therefore, regulators should not dismiss the entire genotype of taxi matchmaking enterprises, but should address the phenotypes that are illegal or that cannot thrive without the illegal behaviors of its users. This conclusion is clear from the structural and directional sides of the practice.
\end{abstract}

\section{Keywords}

normative practice - enkaptic relationships - Uber - aspects - application-based companies

(C) BOSHUIJZEN-VAN BURKEN AND HAFTOR, 2017 | DOI 10.1163/23528230-08202006

This is an open access article distributed under the terms of the prevailing CC-BY-NC License at the time of publication. 


\section{Introduction}

"European court takes up the question: what is Uber?" was the headline of the Financial Times on November 28, 2016 (Robinson and Murgia 2016). Some people consider Uber a taxi enterprise, but Uber declares that it is not a taxi business, but a technology company. Other people categorize it as a ride-sharing software application (i.e., an app) or a taxi network enterprise (Dorenbos 2014).

If the European Court of Justice were to decide that Uber is purely digital, then Uber, with a current estimated market value of USD 63 billion, would have the right to establish its business across Europe. However, if the court were to decide that Uber is an ordinary taxi enterprise, it would not be regulated in Europe as a technology enterprise - it might even be banned. The outcome will influence many other application-based companies that connect independent workers directly to consumers, such as Lyft, Ola, Didi, and Grab. Furthermore, it might be decided that Uber combines some elements of an "information society service" with elements of a taxi enterprise, "creating further confusion for online intermediaries operating within the EU" (Robinson and Murgia 2016). This discussion has been ongoing during recent years, and many newspaper articles have been devoted to either blaming Uber for unfair competition and legal evasions or blaming taxi enterprises for sustaining an unfair monopoly of the taxi industry. Uber has been embraced in some countries, e.g., Estonia (Mardiste 2016), banned in other countries, e.g., the Netherlands (Hellier 2015), and, occasionally, it has voluntarily left a country because it could no longer comply with the laws regulating taxi services, e.g., Denmark (Skydsgaard 2017).

The present investigation addresses the question of Uber's identity by further asking whether and how it is distinguished from an ordinary taxi enterprise. This elaboration brings clarity through a structural analysis of modal functioning and relationships between societal entities. We use insights from reformational philosophy, such as distinctions at the following levels: (1) aspects; (2) radical types, genotypes, and phenotypes; (3) part-whole, enkaptic relationships, and interlinkages; and (4) the distinction between qualifying and foundational functions as it is captured in the theory of normative practices. The overall aim of this study is to clarify a novel complexity created through digital technologies. This analysis shows that the four abovementioned distinctions should not be regarded in isolation. In particular, as to relationships with other societal entities, we identify points of uniqueness in taxi matchmaking enterprises (e.g., Uber) and in ordinary taxi enterprises, as well as commonalities and differences. 
We first present a brief history of the taxi industry and provide a classification of taxi enterprises. We then take on the highly debated case of Uber as an example of taxi matchmaking enterprises and compare it with ordinary taxi enterprises in terms of normative practice-distinguishing between the levels of analysis regarding radical type, genotype, and phenotype-and relationships between entities. This analysis enables us to surface some hidden normative structures that articulate the substantive differences between conventional taxi services and taxi matchmaking transportation.

\section{A Classification of Taxi Services}

First, we consider an assumption often made in the media that has an intuitive appeal. We assume, initially, that Uber is a new type of taxi enterprise. We describe three current types of taxi enterprises from a pre-theoretical perspective, recognizing that, through that process, we might need to revise our assumption and conclude that Uber is not a taxi enterprise. Our descriptions of these three categories focus on the sets of taxi activities by distilling the rules, norms, and procedures of those activities, which are important to the analysis in terms of normative practice.

\subsection{Historical Perspective on Ordinary Taxis}

We distinguish three types of taxi enterprises and name them Single-Cab Firm (SCF), Multi-Cab Firm (MCF), and Non-Cab Firm (NCF). 1 These three types also represent the evolutionary unfolding of the taxi industry in response to the development and utilization of modern information and communication technologies. Currently, these three types coexist. This study assumes that Uber belongs in the NCF category, which is somewhat distinct from SCF and MCF. There may be other active categories of taxi enterprises, but those variants are not relevant to the development of insights into Uber and fall, therefore, outside the scope of the present study. The following analysis and discussion are elaborated for taxi enterprises as understood in the West (Europe and North America). We recognize that there are many minor differences among types

1 We are aware that the concept of Non-Cab Firm might raise questions and sound strange outside the context of this paper, because one could also use "Non-Food Firm" or "Non-Chair Firm" or "Non-Anything Firm." By NCF, we explicitly mean those types of enterprises that operate in the taxi industry which in some way enable customized passenger transit without owning any vehicles to that end. 
of taxi enterprises, but we assume that those differences are irrelevant to our analysis, and they are, therefore, ignored.

\subsubsection{Historical Background}

History informs us that taxis, or cabs, as understood today, emerged in London in the seventeenth century, and they spread quickly to Paris, other key European cities, and New York (Gilbey 1903). They emerged in response to non-London nobilities' desire for private transportation to London for extended visits. Initially, the king prohibited paid in-city horse-drawn carriage transit. However, special permissions were eventually given, which initiated what we now define as taxis. The initial vehicle of transportation - the horsedrawn carriage - was eventually replaced by the automobile, which populated cities quickly.

The key components of a cab are a vehicle, a driver, and a passenger. The passenger can be further differentiated from the customer because customers pay fees (the cab fares) whereas passengers are the persons being transported. Typically, a cab trip comprises passengers that are customers; sometimes, one passenger, who is the passenger-customer, pays the fare while the others are only passengers. Another scenario occurs when the customer is not a passenger - for instance, when parents transport their children by taxi and the parents pay the fare but are not themselves transported. The following analysis, however, does not focus on this distinction; therefore, we omit it to reduce the complexity of the analysis, although we recognize that the distinction might be important in certain situations beyond the scope of this study.

The core task of a cab is to provide customized transit for humans who want it and will pay for it. The term customized means to provide transportation at the desired time from one geographical location to another according to the customer's needs. Customized transit could be contrasted to other types of transit, such as bus, train, or tram, that operate on relatively fixed spatial routes and time schedules with given start and stop destinations, typically for a large group of people, often offering low levels of comfort (standing room and small seats) at a lower fee. This definition identifies the customized temporal and spatial aspects at the core of cab services. Any cab enterprise includes the acquisition and maintenance of a suitable vehicle, which usually is an automobile that offers a significant level of comfort. We are aware that, in some countries, boats, rickshaws, or minivans are used for cab services.

From the beginning, the cab industry in London was regulated. There are several specific regulations on taxi enterprises (Rienstra, Bakker, and Visser 2015). One central regulation concerns the number of cabs permitted to operate in a given area, such as a city. This regulation is sometimes referred to as 
a "medallion," or special permission, to conduct cab services in a given place. Such permissions are regulated and controlled in many countries for a variety of reasons; however, in other countries, there are no such restrictions. London, for example, limits the number of cabs, but neither Stockholm nor Dublin has such limitations (ibid.).

Another key regulation is the need for a special taxi license, which certifies that drivers have successfully passed knowledge and skill tests that qualify them to be taxi drivers. Depending on the country and city, this might include everything from knowledge on cars, the city in which they will operate, how to locate addresses, and how to provide good service to passengers, to application of first aid to people in need. In some places, cabs are required to carry dedicated taxi car insurance. All of these regulations have developed over a period of years, aiming to standardize taxi enterprises and to protect drivers, passengers, customers, and local areas of operation. In addition, there are general regulations with which a taxi enterprise must comply that are the same as for any other enterprise-for example, profit taxation and value-added taxation on profits. Clearly, these and other regulations govern taxi enterprises, and drivers are expected to comply with them.

\subsubsection{The Single-Cab Firm}

The SCF is defined in this study as a vehicle and its driver, legally operationalized as an enterprise offering customized transportation to people for payment. SCF refers to the case where a driver and vehicle are operating independently-as opposed to being part of a taxi enterprise with a fleet of vehicles-and there is no employer-employee relationship other than the cab driver's status as self-employed.

The SCF centers on several core activities that comprise the definition of a cab. One central activity concerns a potential passenger standing on the street and hailing a cab. If a driver and the potential passenger detect each other and the cab is available, the cab driver will stop and the potential passenger will board, often sitting in the rear seat of the car. The driver and passenger then exchange greetings followed by the passenger informing the driver of the desired destination. During transit, the passenger and driver may or may not chat. There is an expectation of certain conventional behaviors, such as politeness; a clean, safe, and reliable cab; that the driver knows how to drive; and that the driver can find the destination. Upon arrival at the desired destination, the passenger will pay the driver (fees are indicated by a taximeter or are fixed prices), perhaps offering a tip, and they will exchange farewells as the passenger exits the vehicle.

A key feature of the SCF is that its operations are limited by time and space because drivers typically obtain their passengers by being signaled from the 
street through visual contact. With the arrival of mobile telephones, some SCF vehicles are ordered via a telephone, which means that the potential passenger and driver determine the pick-up location and time. However, the SCF is limited in terms of space and time: when it is busy transporting a passenger, the SCF cannot pick up another passenger waving in the street or calling on the phone. And since it is not part of a fleet of vehicles with available cars to be sent to the calling customer, such callers will be demotivated to call again. The MCF overcomes the temporal and spatial limitations of the SCF, which is a key factor in the development of the taxi industry.

\subsubsection{The Multi-Cab Firm}

The MCF is defined in this study as a taxi enterprise that owns a fleet of cars and has numerous drivers on its payroll. Historical precedent is important to its evolution with the invention of the shortwave radio. This technology was developed and successfully used for communications during World War II; however, amateur operators in almost all countries were forbidden to transmit radio signals over the air during the war because the frequency bands were needed for military and official communications. The restrictions on its use were lifted after the war and it became accessible to the public beginning in 1950 (see "Taxicab: Regulation" [2017] and "The Golden Age Around the World" [2017]). London taxis were the first to adopt it, which enabled the formation of the MCF. Potential passengers can telephone a call center to order a cab trip by providing the pick-up location and time, and, possibly, the desired destination. Call center operators dispatch an available cab to the pick-up location, communicating the order so that the cab reaches the passenger at the requested time, which, thereby, delivers customized transportation services. Using this communication system transcends the temporal and spatial limitations of the SCF, and an available cab at one location at a given time can be matched to a potential passenger waiting at a different location at the same time. Use of communication technology to match drivers and passengers constitutes a Passenger Feeding Mechanism (PFM) for individual cabs in each type of taxi enterprise. Compared to the SCF, a cab that is part of an MCF is remotely supplied with passenger orders, thereby increasing its utility and, thus, its profit.

Initially, the PFM was developed with analog telephone technology and human operators conducting the matchmaking, but, at present, matchmaking is fully automated through digital technologies. Passengers use the Internet to request a ride, and the MCF sends the order to the available cabs near the pick-up location. Then, one of these cabs accepts the order and is given the pick-up address. Last, the transit service and payment of the fare are executed. 
2.1.4 The Non-Cab Firm

With the advent of Uber, Lyft, Curb, Didi, Grab, and Ola, a new type of taxi enterprise was established which can be understood as uncoupling the PFM from the MCF and independently operating. The PFM has become a separate way to generate profit that has evolved into a software-based enterprise. This means that NCFs do not own any vehicles or employ any drivers - they merely provide matchmaking services between potential passengers desiring transportation and available taxis. Therefore, this type is referred to as non-cab because it does not own or operate vehicles. The key operations of the NCF include obtaining drivers with vehicles to enroll as drivers and obtaining potential passengers for those drivers. The sign-up procedure is conducted over the Internet. A potential passenger downloads a software application, registers her or his name and contact details, and provides a credit card number for automatic and instant payment. Similarly, a potential driver downloads the application for drivers and applies to become a driver. The driver must meet certain conditions, such as having access to an automobile and possessing a driver's license. These conditions vary depending on when and where the transportation occurs. They also vary depending on the company and its branch location; for example, UberPOP and UberBlack have particular requirements for their drivers and vehicles, such as a criminal background check (Feeney 2015; Mirani 2015).

The NCF operates as follows. Once a passenger and a driver have signed up, the passenger directly requests a ride through the PFM of the NCF, which automatically sends the request to nearby available drivers. The information sent with the request comprises the pick-up location, passenger profile, destination, suggested route, and fee. The first driver who wants this order signals through the system that the order has been accepted, and he or she proceeds to pick up the passenger, conduct the trip according to the route suggested by the application, and, upon reaching the destination, receive the fee. The fare is calculated through an algorithm that accounts for supply and demand ("surge price system") and is paid electronically by charging the passenger's credit card. The NCF retains a share of the fee (e.g., 20\%) and remits the remainder to the driver. Figure 1 schematically represents the three types of taxi enterprises discussed in this section.

To analyze the different types of taxi enterprises, we employ insights from reformational philosophy; specifically, the normative practice model (Jochemsen and Glas 1997). 


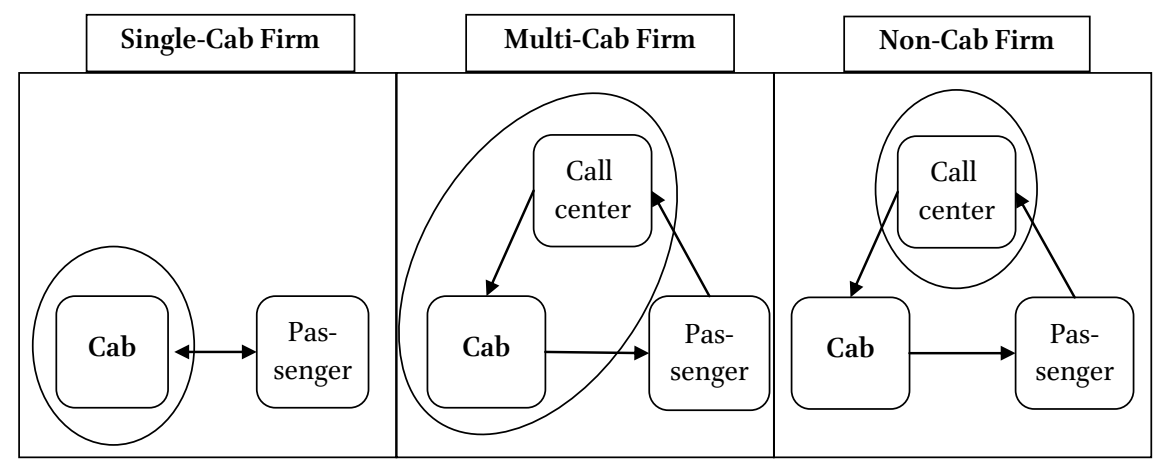

FIGURE 1 The three types of taxi enterprises addressed in this study: Single-Cab Firm, MultiCab Firm, and Non-Cab Firm. The circles represent the respective firms

This analysis is necessary to clarify the way that enterprises, such as Uber, should be classified and assessed. To address the normative character of the current development of taxi enterprises, we use the concepts of structure and direction, which are key to the normative practice model. Jochemsen and Glas define a practice as not merely the collection of specific actions, but as a "socially established complex of related actions, for which a characteristic pattern of norms holds" (Jochemsen and Glas 1997, 27; our translation). A further specification of the "characteristic pattern of norms" is given for the structural aspect of the practice, which, together with the directional side of the practice (see sect. 3.3.), defines the practice as normative.

We add a further insight to the structural analysis, namely, that "there are different types of individuality structures which are different for different groups of things and in which things alternately appear, form themselves or are formed, and disappear" (Dooyeweerd 1953-1958:2, 489). Types can be categorized as radical types, genotypes, and phenotypes (ibid.). In the case of the customized passenger transit provision, specific types of enterprises might appear and disappear, partly depending on the technological possibilities of a given period.

Another useful insight for our study is that individuality structures tend to be enkaptically interwoven and, therefore, things that might initially be considered as "simple" are, in fact, always realized in and constituted by the interstructural intertwinements with other individuality structures (Dooyeweerd 1953-1958:3, 54 and 627). These "intertwinements of individuality structures cannot be posited a priori, but must be discovered in continuous confrontation with empirical social reality" (ibid., 264). Therefore, we pay attention to the relational structures of the entities under observation and to their relationships with other societal structures. 
However, not all relationships are equal. Dooyeweerd distinguishes between part-whole relationships, enkaptic interlacements, and interlinkages (see Chaplin 2011). Dooyeweerd's ontology could help to distinguish a healthy relationship from a distorted one because, according to Dooyeweerd, relationships between entities are normative in character. Therefore, we argue for a further development of the model of normative practice, and we include relationships with other practices and societal entities as a way to determine the normativity of a practice. Not only is inherent normativity important, but it also exists at the borders of the practice where the practice interacts with other structures (Hoogland et al. 1995).

The structure of a practice is characterized by the rules and norms for action that define it. Furthermore, the goal of a practice (its telos) is part of its structure. The body of rules and goals of a practice could be understood as its constitutive aspect. Hoogland and Jochemsen (1997) distinguish among foundational, qualifying, and conditioning constitutive rules. These foundational rules concern the formative side of a practice and "prescribe the activities that give a particular practice its characteristic content" (Jochemsen 2006, 105). These rules often refer to technicalities and ensure the continuation of the practice.

The qualifying rules define the practice's intrinsic destination and reason for existence, and they should guide all other rules. The intrinsic destination of a practice must be clearly distinguished from all external purposes that a practice might pursue (Dooyeweerd 1953-1958). For a business enterprise, the intrinsic destination is economic, which suggests "the sparing or frugal mode of administering scarce goods, implying an alternative choice of their destination with regard to the satisfaction of different human needs" (Dooyeweerd 1969, 66). Verkerk and Zijlstra $(2003,116)$ rephrase this as follows: "The meaning of every business organisation is to produce in an efficient way goods or services for customers in such a way that it gets enough financial returns to continue its existence (including the making of a living by its employees)." Its external purpose might be provision of job opportunities or profit maximization.

The conditioning rules formulate conditions to observe when performing a practice, but they define neither the technicalities of the practice nor its finality (Jochemsen 2006). We recognize that the modern notion of an enterprise (firm) is legally institutionalized, and, therefore, a firm and its business activities must generate at least as much income as it expends in costs over a certain period-typically one year-or cease to exist through bankruptcy. The contextual rules as proposed by several scholars (Glas 2016; Verkerk et al. 2007) somewhat relate to our attempt to focus on relationships with other societal entities—such as regulatory bodies—-through a normative assessment 
of the practice. Competent performance of a practice requires simultaneous compliance with the rules-functioning in the assessment of competent performance as norms - related to the various aspects. Direction refers to the regulating aspect of a normative practice. It has an existential dimension that implies a perspective on what is considered good in life. It involves the variety of basic convictions that drive people to perform their tasks, or the ethos of a profession, influencing the ways the rules are interpreted and developed in daily practice.

\subsection{Individuality Structures}

First, we analyze the structural side of the SCF, MCF, and NCF regarding the relevant factors, focusing on aspectual differences and similarities among the types of taxi enterprises.

\subsubsection{Aspectual Analysis of the SCF}

The ordinary taxi enterprise, the SCF, demonstrates that cab services are about offering customized (in terms of time and space) transportation to people for fees-therefore, it is qualified by the economic aspect. It differs from offering a ride to a neighbor, which is a courtesy or an act of kindness. It further demonstrates that transit services, either for a fee or as a courtesy, are socially based; in other words, there would be no cab services if people were isolated and never interacted with each other.

This taxi enterprise is further conditioned by legal aspects, such as taxi permits and regulations; linguistic aspects, by conveying symbols identifying a vehicle as a cab and conveying meaningful messages about pick-up, destination, and fees; social aspects, wherein driver and passenger behave respectfully toward each other and employ courtesy norms; and moral aspects, such as honesty and fair pricing. There are also pistic aspects, which are religious expressions, such as crucifixes and prayer chains in cabs, and there is a sense of trust ${ }^{2}$ that the vehicle is reliable, the driver has adequate driving skills, and the passenger will pay for the ride. Another conditional aspect involved is the aesthetic aspect, because a cab ride is expected to be smooth, comfortable, and clean. Finally, cab operations employ technological assets and infrastructure (formative aspect), such as streets and vehicular infrastructure (e.g., the production, provision, and maintenance of the vehicles).

2 One reviewer correctly commented that the pistic aspect relates to "ultimate trust" in Dooyeweerd's framework; here, trust should be understood in an analogous sense-economic trust, social trust, and formative trust. 


\subsubsection{Aspectual Analysis of the MCF}

Communication technology enables the MCF to cover a wider geographical area (spatial aspect) than the SCF; hence, its area of coverage and, thus, its potential customer base is larger than that of the SCF. MCFs own numerous vehicles and employ numerous drivers (numerical aspect). The PFM serves the MCF through information exchange; hence, the PFM is qualified by matching passengers with drivers (the analytical aspect) because it is about making distinctions, which is a key element of a successful matching mechanism. Other important aspects of the MCF's PFM are the lingual aspect, in which meaningful information about pick-up location and destination is conveyed, and the social aspect concerning the social interactions among the call center operators, drivers, and customers/passengers. The PFM is formatively founded and characterized by communication technology. The economic costs of the PFM depend on the primary process of the MCF, which is transporting passengers for a fee-therefore, the MCF is economically qualified.

\subsubsection{Aspectual Analysis of the NCF}

NCFs neither own vehicles nor employ drivers, but, because they are not restricted by time or space, they often operate in multiple cities or countries (numerical aspect). In other words, wherever the online application is accessible (spatial aspect), drivers can drive for an NCF, at any time. The two key mechanisms of the NCF are the PFM (formative aspect) and the automatic fee transaction (economic aspect), which are the economically qualified foundational functions of the NCF. Some NCFs, such as Uber, offer drivers and passengers the ability to assess the transit experience through a rating system provided in the application - this relates to the moral aspect because the rating system exists to exclude passengers and drivers who reportedly are "aggressive, violent, or disrespectful" (https://newsroom.uber.com/feedback-is-a-2-way-street/).

The legal aspect of the NCF is complex (see our explanation in the introduction to this paper). Some NCFs, such as Uber's UberPOP branch, allow drivers to sign up as service providers without complying with local regulations; for instance, obtaining permission to operate in a certain region (medallions); waiving the taxi driver's licensing tests or specific insurances on the vehicle, driver, passengers, or other actors in traffic; and/or forgiving taxes, such as VAT or income tax. Strictly speaking, the driver is responsible for violations of the law; however, the NCF is enabling violations and incentivizing drivers to violate the law by offering them "side" jobs.

\subsection{Structure of the Radical Types, Genotypes, and Phenotypes}

In section 2 we provided a pre-theoretical understanding of the historical evolution of the taxi industry, classifying three types of taxi enterprises-SCF, 
MCF, and NCF. These types were contrasted through an aspectual analysis. In this section, we provide a further analytical distinction regarding radical types, genotypes, and phenotypes (or, variability types). Dooyeweerd considered radical types of a secondary order, which typically relate to human social life (Dooyeweerd 1953-1958:3, 90). An analysis of these distinctions might shed further light on the differences that emerged in the pre-theoretical analysis above, particularly with regard to Uber (see figure 2 for an overview).

Radical types determine the distinctive identity or inner nature and destination of a societal structure; for example, the church, which is religiously qualified, or a business, which is economically qualified, or a hospital, which is morally qualified. Genotypes are differentiated radical types which can be "accounted for in terms of the different configurations of modal functions within an individual existent" (Chaplin 2011, 65). In other words, although all concrete entities, such as taxi enterprises, function in each modal aspect, "there are always two aspects in particular that play an essential role in determining their discrete identity, distinguishing them from the identity of others" (ibid., 88), which are the qualifying and foundational aspects. Phenotypes are variations of a genotype that arise from genotypes' interlacements with other, differently qualified structures (ibid.). Therefore, we focus on the structures relative to other structures.

Following Chaplin (2011), the relational structures are defined as follows. In a "part-whole" relationship, the structural requirements of the whole determine the functioning of the part. A part is essentially qualified by the structure of the whole. An "enkaptic interlacement" is characterized by a relationship of subservience, holds only for structures of different radical types, and lacks a distinct structural principle. "Interlinkages" are relationships between formally equal structures of any radical type. ${ }^{3}$

Radical Type: Business The SCF, MCF, and NCF all belong to the radical type of enterprise and are economically qualified because they need to frugally expend resources to maintain existence. A large number of enterprises are advancing the economic aspect by various means and methods, and all actions are guided by the normative principle inherent to business practice of wise allocation and frugality. The foundational aspect of business practice is the formative aspect. An enterprise is founded through intention, creativity, skills, and techniques. Thus, Uber and an ordinary taxi enterprise belong to the same radical type of enterprise, which is a normative practice. However, if we

3 Various translations of Dooyeweerd's term maatschapsverhoudingen have been proposedfor example, "juxtapositional relationships" (Van Burken and De Vries 2012)—and one reviewer suggested that Dooyeweerd himself used the term "correlative enkapsis." We follow Chaplin (2011), who used the term "interlinkage." 
distinguish at the genotype level, differences immediately become apparent, as described below.

Genotype: Customized Passenger Transit Company An SCF or an MCF is characterized by owning one or a fleet of cars and employing drivers to offer private transit-as opposed to trains or buses, which offer public transit. Therefore, they are examples of the genotype customized passenger transit enterprise with the primary function of facilitating passenger transit via private vehicle with a driver for a fee. Private passenger transit occurs for many different reasonse.g., socializing, employment, caregiving, or shopping — and is qualified by the social aspect. A taxi enterprise is a specific response to a basic human need for social interaction by means of the radical type of an enterprise, the latter being economically qualified. Other ways to respond to this basic human need (for instance, public transit) belong to a different radical type-to wit, public services-which is qualified by the legal aspect. Another way to facilitate social interaction is to offer free rides to friends, neighbors, or colleagues; this belongs to the radical type of volunteer efforts, which are morally qualified. When the basic human need for social interaction disappears, the reason for a passenger transit enterprise ceases to exist. There is also transportation of goods and services, which we exclude from this analysis. We do recognize that a taxi might be used to transport goods, but in many countries these rides are not considered as taxi rides but as transportation of goods. Therefore, they fall under different law and tax schemes (Royal Dutch Transport Federation 2017). The foundational function of the private passenger transit enterprise is formative because it needs a vehicle to accomplish its primary process.

Phenotype: Taxi Services SCFs and MCFs are different phenotypes within the genotype of customized passenger transit that could be defined as "taxi services." There are relational differences; for example, the driver of an SCF is an independent worker who owns the vehicle, whereas the MCF owns a fleet of vehicles and employs numerous drivers. In the MCF and the SCF, the vehicle has a part-whole relationship to the enterprise - without a vehicle, the enterprise's primary process stops. The driver is enkaptically interwoven with the enterprise by a contract, which implies a hierarchical relationship. The driver is not completely free to decide when and where to work, and he or she depends on the demands of the taxi enterprise.

Genotype: Transit Matchmaking Company In contrast to SCFs and MCFS, NCFs belong to the transit matchmaking enterprise genotype. Uber, for example, neither owns cars nor employs drivers. There are different ways to operate transit matchmaking enterprises-for instance, on the Internet, or through a central telephonic service. This genotype's primary process concerns maintaining and keeping its technological platform current for establishing 
successful matches between people in need of customized vehicle transport and the available vehicles. Within the radical type of an enterprise, the qualifying function of the transit matchmaking enterprise is social because its primary process is to connect passengers to drivers. Other technological platforms that match passengers to drivers do not belong to the radical type of enterprise because they make the connections for free through open software (e.g., LibreTaxi and Carpooling Open Source Ride-Sharing Application [Bonarrigo et al. 2014]). These platforms might belong to the radical type of volunteer organizations (morally qualified) and fall outside the scope of this analysis.

Thus, the qualifying function of a system that matches passengers to drivers is social, but this qualifying function could be found in numerous radical types (with different qualifying functions). Uber is operationalized within the radical type of an enterprise (economically qualified). The foundational function of the NCF is formative because its functioning depends on its platform, and it is further conditioned by the communications technology infrastructure, such as Internet access and availability of smartphones. There could be contracts between drivers, passengers, and transit matchmaking enterprises, but there is no hierarchical relationship; therefore, they form an interlinkage. Transit matchmaking enterprises' drivers are free to work whenever and wherever they please.

Phenotype: Application-Based Transit Matchmaking Company Uber, as an NCF, belongs to the phenotype of application-based transit matchmaking enterprises. There are other enterprises in that phenotype (for instance, Lyft, Ola, Didi, and Grab) that all use smartphone applications. In the radical type

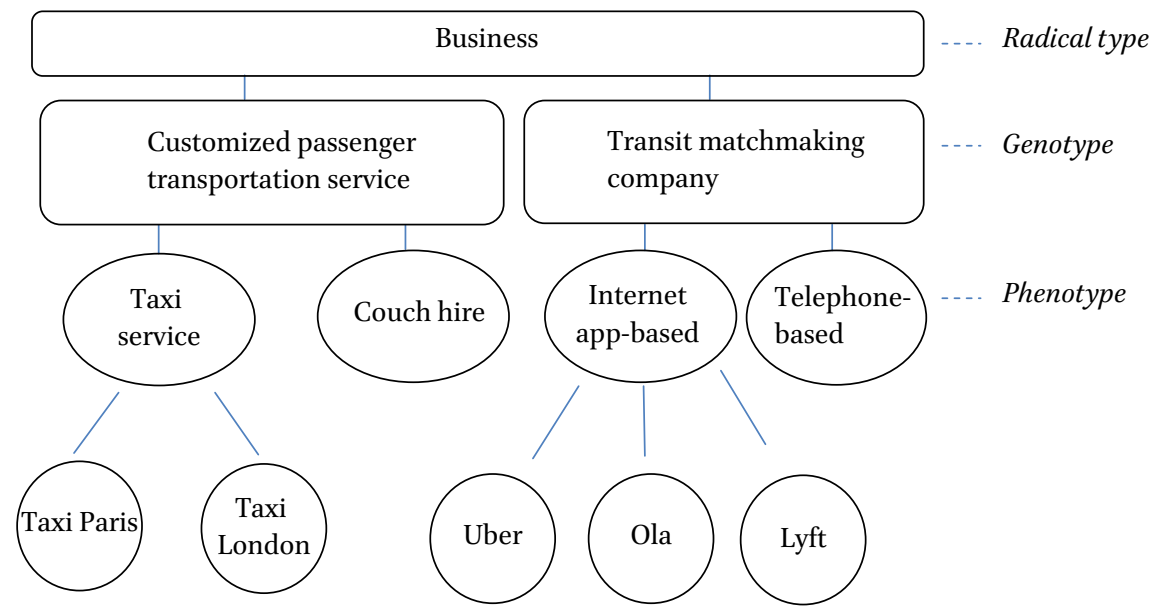

FIGURE 2 The structural organization of the entities involved in the types of taxi enterprises in this study: radical types, genotypes, and phenotypes in the taxi industry 
of enterprises, their qualifying function is social because they connect drivers to passengers. The foundational function is formative because its primary process depends on the operating system or passenger feeding system (PFM), which entails keeping an application operating. The PFM performs the primary process of the phenotype, and it is not subservient to the primary process, as in the case of the MCF. The PFM has a part-whole relationship to the application-based matchmaking enterprise because it cannot be removed from the primary process. Without the PFM, application-based transit matchmaking enterprises could not be meaningfully understood.

\subsection{Direction}

The previous section analyzed types of matchmaking services for taxi transport services. Using various analytical tools, we indicated some key aspects of taxi enterprises in general, and of Uber in particular, in more or less functional terms. This section addresses the directional side of a practice, which is an important part of normative practice analysis. Direction refers to the regulative side of a normative practice in which worldview and ethos have roles. A direction for Uber is, for example, to "conquer the world" by making their application available everywhere- this can be inferred from their slogan "Available Locally, Expanding Globally" (https://newsroom.uber.com/locations/)—or to "contribute to a more sustainable environment." Taxi companies that consider a sustainable environment important are likely to make this directional side of the practice tangible in the structural side of the practice; for instance, by requiring restrictions on $\mathrm{CO}_{2}$ output on the vehicles that drive for them.

It is clear that Uber attaches little value to respecting regulatory bodies. It enables and incentivizes illegal taxi services because it operates the application in countries where special permits are needed for paid passenger transit. Uber's drivers use their personal cars and often lack the required permits and licenses to conduct paid passenger transit. Uber is not directly engaged in illegal activities, but it invites and enables non-compliance by its drivers, which indicates a worldview that questions and disrespects the authority of regulatory bodies. The directional side influences the structural side of the practice because, as a rule, Uber pays the fines that the drivers incur (Alderman 2015). Similarly, the directional norm of non-compliance has changed a tacit norm of ordinary taxi enterprises, namely, that a passenger sits in the rear seat of the vehicle, into the new norm - at least in countries where driving for Uber is illegal—of seating passengers up front next to the driver. This practice lowers the risk of fines because doing so disguises the Uber cab as a non-taxi vehicle (ibid.). 
It is important to note that the "normativity" in the concept of normative practice is constitutive as well as regulative. In other words, practices are normative in what constitutes them as well as in what regulates them. The importance of both aspects opens up ways to assess newcomer Uber and ordinary taxi practice. Ordinary taxi enterprises are known for their aggressive and restrictive market competition, which is a directional norm that sometimes leads to a crisis in the taxi industry. A good example is the taxi war in the Netherlands in 2000, in which a driver killed a potential passenger over a price dispute ("Taxioorlog" [Taxi war] 2017).

Witt, Suzor, and Wikström $(2015,177)$ observed the following about regulating NCFs (such as Uber) which might be applicable to the taxi industry in general.

A substantial part of the battle is actually being waged as an ongoing ideological conflict between different conceptions of the appropriate role of the state, algorithms, and markets. This ideological conflict is supplemented in rich and complex ways by strong and often conflicting rhetoric of decentralization, liberation, communitarian sharing, and anti-consumerism.

In short, the directional side of a new or pre-existing practice produces as much conflict as the structural side of the practice.

In the theory of normative practices, fairness to all aspects is the key to the flourishing of the practice and to the flourishing of the society in which it functions. SCFS, MCFS, and NCFS do not operate in a void but in a context that is richer than a mere economic business climate. For example, a business must give priority to the economic aspect, but it will not succeed in the long term if it does not pay attention to the social, legal, and pistic aspects. As to Uber, it is clear that no consideration has been given to the legal aspect because many Uber drivers do not obey the rules and regulations on customized passenger transit. The fact that not all taxi enterprises operating under the NCF business model violate these regulations indicates that NCFs are sometimes legal operations. The owners decide how to operate, and they choose to demand compliance from the drivers or to ignore violations. Significant economic value creation seems to be a strong motivation for some NCF owners to choose to indirectly contribute to illegal practices. In other words, because more rides means more transactions, and banning drivers who do not comply with the rules means less profit, many rides are provided by non-compliant drivers. Uber aims to convince regulators that the laws on customized passenger transit do 
not apply to them because of their internal rating system. Uber's disrespect for the legal aspect has already caused their UberPOP branch to cease operating in some countries, such as the Netherlands ("Uber drops Uberpop taxi service in the Netherlands" 2015).

\subsection{Relational Similarities and Differences between Uber and Ordinary Taxi Enterprises}

Uber and ordinary taxi enterprises have at least two things in common: (1) they are a radical type of an economic entity (a business enterprise) and (2) they operate in the customized passenger transit industry. They share the same qualifying principle with respect to radical types, but they differ in the foundational aspect. Uber's foundational rules relate to software applications, whereas the other taxi enterprises' functioning concerns their vehicles and drivers. Both types operate in the same market industry and are therefore interlinked, although enterprises do not have the same foundational function. Through its foundational function, which is typical of the transit matchmaking genotype, Uber could operate in other industries, such as the freight industry. It could use a slightly adapted version of its software to connect "that what needs to be transported" to "that what can transport it," which is how Uber actually operates (see "We're in for the long haul" 2017).

Some of the key features of the normative practice of ordinary passenger transit are quite different from a digital matching system between passengers and drivers. First, several norms in the pre-theoretical understanding of the SCF and MCF do not exist in the case of NCFs. For example, standing on the street and hailing a taxi is not normative for NCFs, there is no need to tell drivers where to go because of the online servicing, and the physical act of paying drivers for services does not exist in such phenotypes as Uber (Gillett 2016). In the case of NCFs, the focal point of attention shifts from a visual focus on cars, faces, fare rates, taximeters, and coins to the smartphone monitor.

Second, the situation is different with respect to relationships. Although the relationship between driver and passenger is interlinked in an NCF as well as in an SCF and MCF, the NCF online service requires a customer's acceptance of the terms and conditions for using the service, and through this constitutive rule of the NCF, the customer's anonymity cannot be guaranteed. In Uber's sign-up process, a formal legal and economic relationship between customers and Uber is established through agreements that stipulate legal conditions for their interaction and relationship, and in 2016 Uber was blamed for privacy breaches (Carson 2016). This formal legal relationship is absent from the SCF and the MCF. 
The NCF also assumes a trust relationship exists because the customer provides Uber with credit card details, which could be misused. The trust relationship with an NCF differs from that of an MCF or an SCF. In the SCF and the $\mathrm{MCF}$, the trust relationship exists between the passenger and the driver because the passenger must trust that the driver knows the route and is a skilled driver, and the driver must trust that the passenger will pay the fee at the end of the ride. However, the route and payment are automatically handled by the online system of the NCF-therefore, the trust relationship has shifted from the driver and passenger to the PFM and customer. Nevertheless, trust in the PFM might be hindered by technological failures, privacy concerns, or nontransparency of the PFM algorithm.

\section{4}

\section{Discussion}

The model of normative practice was introduced and has developed during the past few decades, and its main use has been to improve understanding of existing practices (e.g., MacIntyre 1981), such as medical practice, military practice, and engineering practice. It was intended to demonstrate that normativity is not externally imposed upon a practice, but that practices are inherently normative.

In this study we had a somewhat different goal, namely, to understand a novel entity in society-i.e., transit matchmaking enterprises, of which Uber is an example. Uber's situation has raised several societal challenges through its disruptive technology, the Uber online application. The question we asked is whether Uber is a further development of an existing practice (taxi enterprises) or a totally new practice requiring new qualifying and foundational norms and new conditioning rules and regulations. We gained insight into this matter and brought the inherent normativity of the practice to the forefront by analyzing Uber in terms of its structure and direction.

Our question is relevant because it categorizes an interesting phenomenon; but more importantly, the answer to this question helps governmental and other entities decide on an appropriate response to Uber that does not slow societal progress nor embrace a novelty harmful to society. Our analysis aimed to contribute to responsible societal and technological progress rather than limit it. Therefore, understanding the normative development of new phenomena - such as Uber - is helpful, and we propose that the model of normative practice, with some extension, helps to determine the normative direction of this particular practice. 
The strength of the normative practice model is that it harmonizes two approaches. On the one hand, types of enterprises in the passenger transit industry can be understood in purely functional terms - that is, in terms of what they do as their primary process. On the other hand, the enterprises can be understood in terms of their ultimate objectives (telos) and a worldview perspective, considering what they enable or incentivize and the ways that they fulfill human needs.

Considering Uber (and Uber-like enterprises) from the purely functionalist approach identifies it is as merely a smart digital platform that enables geographical information exchange between smartphones and an automatic payment system. Considering Uber in terms of its ultimate goal and direction, it provides passenger transit in a novel way. It incentivizes ordinary automobile owners to transport passengers for a fee. ${ }^{4}$ Uber explicitly states that it aims to transform the way that people commute: its website (www.uber.com) states that Uber wants to "make transportation as reliable as running water." This approach differs from the functional description of Uber as merely a technology firm which omits references to commuting or transportation (which Uber uses in court).

Ordinary taxi enterprises argue that Uber is cheating in the customized passenger transit industry because it evades the laws and norms relevant to paid passenger transit. Uber, however, argues that it is not cheating because it is not a taxi enterprise, which means that the rules and regulations do not apply to it. Our analysis found that Uber is in the taxi matchmaking business in which, as yet, no relevant positive laws or norms exist, and that it relates to the regulatory bodies distinct from ordinary taxis.

However, Uber drivers do behave as though they are part of a passenger transit enterprise, although they do not consider themselves part of an enterprise, despite the fact that they are driving passengers to destinations for fees, without enkaptic interlacement with Uber. The drivers incur costs and make investments (e.g., fuel), and they receive fees for the rides they provide, aiming to profit thereby and - in principle - act within the normative framework of a business practice. Apart from the fact that most Uber drivers are not registered as businesses, it is questionable whether all of the drivers comply with the guiding principle of the normative practice (frugality) because there is some question about the benefits of driving for Uber (Brown 2016). Uber drivers tend to forget that they should carefully calculate the costs, such as insurance, car amortization, fuel, maintenance, parking costs, and taxes. Calculating costs,

4 Uber states: "Across borders, cultures, and languages, we're proud to connect people who need a reliable ride with people looking to earn money driving their cars" ("Finding the way. Creating possibilities for riders, drivers, and cities" 2017). 
benefits, and risks is a normative principle of any economically qualified business enterprise. However, some drivers are unaware of or misinformed on these matters, and they operate contrary to normative business principles.

Although it might be unclear whether Uber drivers act according to the qualifying principle of a taxi enterprise, they do violate the legal principles of paid passenger transit that exist in many countries. Under that condition, Uber is a technology company that invites and enables illegal behaviors in the passenger transit industry. However, new companies such as Uber have pointed to overregulation of the passenger transit industry which seems to protect unhealthy monopolies in the industry rather than to safeguard values-e.g., the safety, transparency, fairness, and reliability of passenger transit. Therefore, regulators and policy makers should reconsider the current policies in light of evolving societal values; they should be open to technological developments, such as smartphone application-based enterprises, that support societal values, and establish rules and regulations regarding technologies and enterprises that undermine values and norms.

\section{Conclusion}

This paper first provided a historical perspective on the taxi industry and supported it with a pre-theoretical classification of types of taxi enterprises, including Uber. Second, we analyzed taxi enterprises in the scheme of normative practice, with distinctions between structure and direction. The structural analysis was further broken down by the analytical distinction between aspects, types (radical, genotypes, and phenotypes), and relationships (partwhole, enkaptic interlacements, and interlinkages).

The analysis focused on the passenger transit industry in which various entities interact. We found that transportation could occur for a variety of reasons qualified by the social aspect-e.g., socializing, employment, caregiving, and shopping. We further focused on enterprises that respond to these needs as business opportunities, so that SCFs, MCFs, and NCFs all belong to the same radical type of enterprise and have in common that their primary function is economically qualified. The foundational functions of the genotypes differ in their character. The foundational functions of SCFS and MCFs are in the formative aspect of maintaining and operating one or more vehicles and, in the case of the MCF, the drivers are either employees or contractually bound to the enterprise. The foundational function of the NCF is in the formative aspect of operating and maintaining an online communications platform. We named this communications platform the passenger feeding mechanism ( $\mathrm{PFM}$ ). For the MCF, the PFM plays a subservient role in the enkaptic relationship between 
the PFM and MCF; the PFM has a cost function in the MCF. For the NCF, the PFM has a part-whole relationship, meaning that the NCF derives its meaning from the PFM. For NCFs to function as businesses (economically qualified), the PFM must operate frugally.

The relationship between an MCF and its drivers is an enkaptic interlacement because of the employment contracts, which are hierarchical relationships. The passengers are interlinked in the SCFs and MCFs and there are no hierarchical relationships. The NCFS and the PFM are interlinked as well, but the interlinkage tends towards enkaptic interlacement because of the sign-up procedure that entails acceptance of terms and conditions, which creates a legally binding relationship.

Our conclusion is that the genotype of transit matchmaking enterprises, of which Uber is an example, should not necessarily be problematic. Problems might emerge from the way Uber is operationalized in various phenotypes because of unsettled legal and moral issues. Consequently, rather than dismiss the entire genotype of taxi matchmaking enterprises, regulators should address those that are illegally operating or that profit from the illegal behaviors of their users.

In this paper, we limited our investigation to the relationships among drivers, passengers, cars, platforms, and taxi enterprises, but insurance companies, regulatory bodies, credit card companies, and others could also have been included.

Based on the present analysis, we conclude that not all relationships are equal, and specifications of part-whole relationships, enkaptic interlacements, and interlinkages are helpful for determining which enterprises do act with honesty and fairness in their relationships with societal entities, and which do not. From our perspective, only those enterprises that act fairly toward structural diversity in their relationships will survive over the long term. For example, Lyft stems from the same phenotype as Uber, but it responds differently than Uber does to legal challenges. Unlike Lyft, Uber often chooses non-compliance as a business strategy. Lyft also is known for its friendly work culture, whereas Uber has significant problems in that area. Lyft has been rated relatively better regarding relationships to drivers, passengers, and regulatory bodies (see, for example, a comparison of their ride-sharing applications ["Uber vs Lyft" 2016]). Our analysis and conclusions presented here preceded Uber's current, severely damaged reputation. ${ }^{5}$ However, our

5 We have been following discussions on application-based companies over the past few years, but just before the submission of this paper's revised version, Uber peaked in negative attention, with some people referring to the "moral bankruptcy" of the company. Uber's founder and CEO resigned on June 21, 2017 (Hawkins 2017; O’Reilly 2017; Spiegel 2017). 
conclusion echoes Steinmetz and Vella's (2017) assessment that "If Uber's stunning stumble proves anything, it's that in the absence of any rule makers that can keep up with them, the architects of the new economy-which may be another way of saying, the new world-must hold themselves accountable" (Steinmetz and Vella 2017).

Last, we add that accountability can be understood only in terms of relationships. In Uber's case, these are relationships with drivers, passengers, competitors, regulatory bodies, and so on. In this paper, we attempted to clarify these relationships with respect to Uber because we believe they are important for understanding the normative structure of the practice of customized passenger transit.

\section{References}

Alderman, L. (2015). Uber's French Resistance. New York Times Magazine, June 3. Accessed April 22, 2017. https://www.nytimes.com/2015/06/07/magazine/ubers -french-resistance.html.

Bonarrigo, S., Carchiolo, V., Longheu, A., Loria, M., Malgeri, M., and Mangioni, G. (2014). A Carpooling Open Application with Social Oriented Reward Mechanism. In: G. Fortino, G. Di Fatta, W. Li, S. Ochoa, A. Cuzzocrea, and M. Pathan, eds., Internet and Distributed Computing Systems, Cham: Springer, pp. 447-456. https://doi .org/10.1007/978-3-319-11692-1_38.

Brown, B. (2016). How Much Do Uber Drivers Really Make? Accessed April 28, 2017. http://www.digitaltrends.com/cars/uber-driver-earnings/.

Carson, B. (2016). Uber settles investigation into "God View" tool. Accessed April 22, 2017. http://www.businessinsider.com/uber-settles-investigation-into-god-view -tool-2016-1?international=true\&r=US\&IR=T.

Chaplin, J. (2011). Herman Dooyeweerd, Christian Philosopher of State and Civil Society. Notre Dame: University of Notre Dame Press.

Dooyeweerd, H. (1953-1958). A New Critique of Theoretical Thought. (4 vols). Amsterdam: Paris; Philadelphia: The Presbyterian and Reformed Publishing Company.

Dooyeweerd, H. (1969). A New Critique of Theoretical Thought. Volume 2, The General Theory of the Modal Spheres. $2^{\text {nd }}$ ed. Philadelphia: The Presbyterian and Reformed Publishing Company.

Dorenbos, A. (2014). Is the Ride Right? Transportation Network Companies and Taxicabs. Oxera (August), pp. $1-5$.

Feeney, M. (2015). Is Ridesharing Safe? Cato Policy Analysis 767, p. 2.

Finding the way. Creating possibilities for riders, drivers, and cities. (2017). Accessed April 28, 2017. https://www.uber.com/en-NL/our-story/.

Gilbey, W. (1903). Early carriages and roads. London: Vinton \& Company Ltd. 
Gillett, R.(2016).Uberdrivers say, yes, you should tip them. Accessed April 29, 2017.http:// www.businessinsider.com/uber-drivers-you-should-tip-2016-12?international $=$ true $\& \mathrm{r}=\mathrm{US} \& \mathrm{IR}=\mathrm{T}$.

Glas, G. (2016). Reinventing Professionalism-Public Responsibility in Current Medicine and Psychiatry. Paper presented at the International Conference "Christianity and the Future of Our Societies," Leuven, August 2016.

Hawkins, A.J. (2017). Can Uber be saved from itself? Accessed July 5, 2017. https:// www.theverge.com/2017/3/6/1479108o/uber-sexism-scandal-strike-waymo-lawsuit -travis-kalanick.

Hellier, D. (2015). From Rio to Paris-Uber is fighting battles across the globe. The Guardian, October 2. Accessed October 13, 2017. http://www.theguardian.com/ technology/2015/oct/o2/uber-global-battles-from-rio-paris-amsterdam.

Hoogland, J., and Jochemsen, H. (1997). De normatieve structuur van de medische praktijk. In: H. Jochemsen and G. Glas, eds., Verantwoord medisch handelen. Proeve van een christelijke medische ethiek, Amsterdam: Buijten \& Schipperheijn, pp. 64-99.

Hoogland, J., Jochemsen, H., Polder, J.J., and Strijbos, S. (1995). Professioneel beheerst. Professionele autonomie van de arts in relatie tot instrumenten voor beheersing van kosten en kwaliteit van de gezondheidszorg. Rapport van het Prof. dr. G.A. Lindeboom Instituut (no. 12). Ede: Prof. dr. G.A. Lindeboom Instituut.

Jochemsen, H. (2006). Normative practices and theoretical ethics and morality. Philosophia Reformata 71 (1), pp. 96-112.

Jochemsen, H., and Glas, G. (1997). Verantwoord medisch handelen. Proeve van een christelijke medische ethiek. Amsterdam: Buijten \& Schipperheijn.

MacIntyre, A. (1981). After Virtue: A Study in Moral Theory. London: Duckworth.

Mardiste, D. (2016). Embracing Uber, Estonia shows tax needn't be an issue. Accessed October 13, 2017. http://www.reuters.com/article/us-estonia-uber-idUSKCNoYV1PS.

Mirani, L. (2015). How Uber hires drivers where background checks are impossible. Accessed April 28, 2017. https://qz.com/473905/how-uber-hires-drivers-where -background-checks-are-impossible/.

O'Reilly, T. (2017). Uber's Opportunity to Remake Silicon Valley-For Good. Accessed July 5, 2017. https://www.wired.com/story/uber-scandal-opportunity-to-remake -silicon-valley-for-good/.

Rienstra, S., Bakker, P., and Visser, J. (2015). International comparison of taxi regulations and Uber. Accessed October 13, 2017. https://english.kimnet.nl/publications/ reports/2015/05/06/international-comparison-of-taxi-regulations.

Robinson, D., and Murgia, M. (2016). European court takes up the question: what is Uber? Financial Times, November 28. Accessed April 25, 2017. https://www.ft.com/ content/f2774c9a-b566-11e6-ba85-95d1533d9a62.

Royal Dutch Transport Federation. (2017). U vervoert goederen in de taxi. Accessed April 28, 2017. https://www.knv.nl/taxi/veelgestelde-vragen-bct/22/u_vervoert _goederen_in_de_taxi/. 
Skydsgaard, N. (2017). Uber is ending its services in Denmark. Accessed May 5, 2017. http://www.businessinsider.com/uber-ending-services-in-denmark-2017-3?interna tional $=$ true \& $r=U S \& I R=T$.

Spiegel, D. (2017). Uber CEO Travis Kalanick's war with Lyft for car's future isn't over. Accessed July 5, 2017. http://www.cnbc.com/2017/05/16/uber-ceo-travis-kalanicks -war-with-lyft-for-cars-future-isnt-over.html.

Steinmetz, K., and Vella, M. (2017). How Upheaval at Uber Is a Wake-Up Call for Silicon Valley. Accessed July 5, 2017. http://time.com/4819557/uber-fail-upheaval-is -wake-up-call/.

Taxicab: Regulation. (2017). Wikipedia, last modified October 12, 2017. Accessed July 3 , 2017. https://en.wikipedia.org/wiki/Taxicab\#Regulation.

Taxioorlog [Taxi war]. (2017). Wikipedia, last modified October 4, 2017. Accessed April 28, 2017.https://nl.wikipedia.org/wiki/Taxi_(vervoer)\#Taxioorlog_en_onrust.

The Golden Age Around the World. (2017). Accessed July 3, 2017. https://www.britannica.com/topic/radio/The-Golden-Age-around-the-world.

Uber drops Uberpop taxi service in the Netherlands. (2015). Accessed October 13, 2017. http://www.dutchnews.nl/news/archives/2015/11/uber-drops-uberpop-taxi -service-in-the-netherlands/.

Uber vs Lyft: Comparing the Rideshare titans. (2016). Accessed July 5, 2017. https:// rideshareapps.com/uber-vs-lyft-comparison/.

Van Burken, C.G., and De Vries, M.J. (2012). Extending the Theory of Normative Practices: An Application to Two Cases of Networked Military Operations. Philosophia Reformata 77 (2), pp. 135-154.

Verkerk, M.J., Hoogland, J., Van der Stoep, J., and De Vries, M.J. (2007). Denken, ontwerpen, maken. Amsterdam: Buijten \& Schipperheijn.

Verkerk, M.J., and Zijlstra, A. (2003). Philosophical analysis of industrial organisations. Philosophia Reformata 68 (2), pp. 101-122. https://doi.org/https://doi.org/ $10.1163 / 22116117-90000286$.

We're in for the long haul. (2017). Accessed July 1, 2017. https://freight.uber.com.

Witt, A., Suzor, N., and Wikström, P. (2015). Regulating ride-sharing in the peer economy. Communication Research and Practice 1 (2), pp. 174-190. 